\title{
Managing conflicts of interest: who, and how?
}

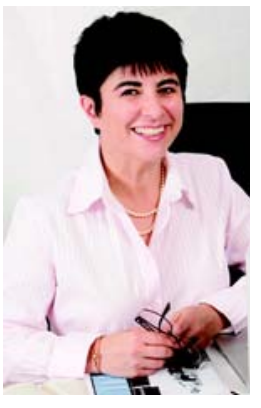

Annette Katelaris Editor akatelaris@mja.com.au doi: 10.5694/mjal2.c0416 Australian universities" (page 452) is timely. Chapman and colleagues investigated the state of disclosure policies in Australian universities and the level of public access to disclosure information. Their findings are concerning. A third of universities declined to participate, for unclear reasons. Only eight universities maintained a central register of COIs for all staff, and two universities had policies stating that information regarding COIs would remain confidential. Without regulations in place at the university-wide level, medical faculty attempts to manage COIs will become toothless.

Transparency is vital for managing medical COIs. Institutions must provide the right environment and policies for their staff, and the institution itself, to encourage "clean" research and practice, leading to valid knowledge and useful treatments. The assessment of medical faculty and hospital campus regulatory efforts have been informed by these principles in the United States (Acad Med 2011; 86: 293-299) and, more recently, in Australia (Med J Aust 2011; 194: 121-125). However, these studies revealed significant policy variation and gaps, incomplete efforts, and failures to report on regulations governing COIs. Australia's efforts lag considerably behind those of the US.
The issues are magnified for those who are leaders in the profession, for whom industry involvement is a two-edged sword. Dr Bernard Lo, of the University of California, San Francisco, summarises the issues (N Engl J Med 2010; 362: 669-671): relationships with pharma are trade-offs between new treatments and knowledge translation and the industry's desire for new products, markets and profits - trade-offs that are more acute for key opinion leaders. However, any relationships must be at arm's length. Nor should they be seen as a professional status symbol with significant personal perks. Without effective COI management, our leaders will turn into what would essentially be sophisticated sales staff, and their publications and any guidelines they present would become advertorials.

The effects of COIs extend beyond the individual involved. Our students and doctors-in-training develop values and knowledge from working with their mentors. They, and the community, need to feel sure that they and their teachers are working primarily in their patients' interests rather than those of pharma. Should an academic be teaching medical students or mentoring junior doctors while on pharma's books as a key opinion leader?

But still the question remains: after public declaration of COIs, what then? Academic institutions must investigate and intervene where there are concerns to ensure that research and teaching is not biased or coerced. This protects the academic and the institution. Who should do the investigating? Hopefully, when the University of Sydney looks at the Hickie issue that was raised in The Lancet - as they must - it will be done at arm's length and the investigators will have at their disposal a policy that enforces accountability.

Medicine's involvement with industry will continue to be a reality - for good or bad. Pharma clearly needs us. We should be using the power that that gives us to rethink our industry relationships on our terms and in the interests of the community. And, hopefully, pharma will also realise that an independent medical profession is in its interests too.

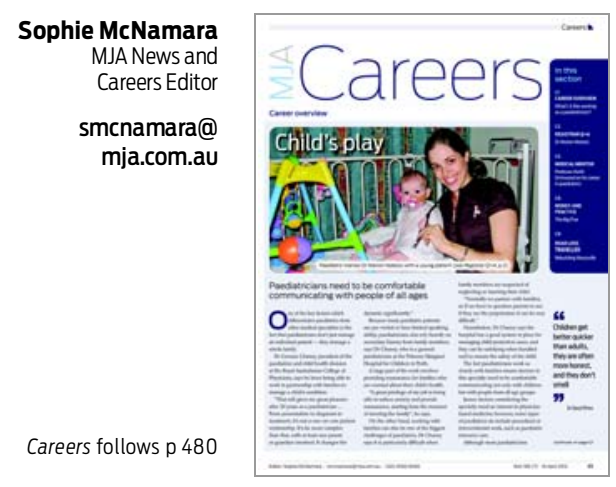

\section{A financial health prescription}

While doctors spend years training to develop clinical skills, their financial skills may not be as well honed. In this issue of MJA Careers, the Money and Practice section highlights the top five financial mistakes that doctors make, according to financial advisers who specialise in the health sector (page C6). The story explains how to avoid the common pitfalls so that you can turn a healthy cash flow into ongoing wealth. Also in this issue, we look at what's involved in training and working as a paediatrician (page C1) and speak to a prominent paediatrician who has been involved in several groundbreaking research projects (page C5). Finally, Road Less Travelled focuses on a rural general practitioner who lost his home and clinic in the 2009 bushfires in Victoria and has since thrown himself into recovery efforts (page C9). 